\title{
Argentina, EStocolmo, NeTFliX Y EL SÍNDROME DE LA IDENTIDAD PERDIDA
}

\author{
Argentina, Stockholm, Netflix and the Syndrome of Lost Identity
}

\author{
KSENIJA BILBIJA \\ University of Wisconsin-Madison (EE.UU) kbilbija@wisc.edu
}

\author{
RECIBIDO: 22 DE MARZO DE 2018 ACEPTADO: 14 DE ABRIL DE 2018
}

RESUMEN: Aunque la trama principal de la primera serie policial argentina de Netflix Estocolmo: Identidad perdida (2017) gira alrededor de un referente globalizado — la trata de mujeres_ este thriller noir es una producción cultural del neoliberalismo que manipula el trauma del pasado dictatorial (1976-1983) por medio del uso de símbolos asociados con la memoria histórica argentina. A través del prisma de la patología del síndrome de Estocolmo (no reconocido por la Organización Mundial de la Salud y de etiología desconocida) la serie espectaculariza el cuerpo femenino, sugiriendo que las mujeres son cómplices de su propia opresión. En la jerga global mediática, el síndrome de Estocolmo ha llegado a denotar un "amor perverso" que lleva implícita la fascinación con la violencia y el sexo, incluyendo la violación y esclavitud sexual. La lógica del mercado privilegia la representación de la mujer como persona que acaba sometiéndose "voluntariamente" al poder de su victimario, mostrando así que su sexualidad sigue siendo propiedad del hombre.

PALABRAS CLAVE: Argentina, dictadura militar, Síndrome de Estocolmo, feminicidio, género sexual.

ABSTRACT: While the plot of the first Argentine series made for Netflix Stockholm: Lost Identity (2017) revolves around a globalized referent — sex trafficking and slavery — this noir thriller is a cultural product of neoliberal politics in that it manipulates a past trauma related to the dictatorship (1976-1983) through its use of the symbols associated with Argentine historical memory. By using the prism of Stockholm Syndrome (one not recognized by the World Health Organization and with unknown etiology) the series transforms the female body into a spectacle, suggesting that women consent to and even enjoy their own oppression. In the jargon of the global media, Stockholm Syndrome denotes "perverse love" and implies a fascination not only with violence and sex but also with rape and sexual slavery. The market logic privileges the representation of women who ultimately subject themselves "voluntarily" to the power of the victimizer, showing that their sexuality belongs to men.

KEYWORDS: Argentina, Military Dictatorship, Stockholm Syndrome, Femicide, Gender. 
A mediados de noviembre del 2016, ochenta y seis millones de personas en unos ciento noventa países pudieron ver, a la hora que más les convenía y con tal de que hubieran pagado su cuota mensual, el estreno de la primera serie argentina en llegar a Netflix. ${ }^{1}$ Uno de sus creadores, Nacho Vale, sostiene que es 100\% argentina en cuanto a la producción, pero no aparecen en ninguno de sus trece episodios ofrecidos al público global los íconos tradicionales asociados con el país: ni el tango, ni el fútbol, ni el mate, ni los gauchos, ni el Che, ni Evita, ni Maradona.2 Aún más, el título de la serie, Estocolmo: Identidad perdida no hace referencia directa al segundo país más grande de América Latina ni a su capital, sino que contiene el topónimo de la muy distante capital de Suecia. Siendo una ficción televisiva policiaca, una serie de investigación judicial, criminal y mediática que gira alrededor de los misteriosos secuestros y asesinatos de mujeres jóvenes, uno podría asumir que la invocación de la capital sueca podría ser un intento de aprovecharse de la marca ciudad de la que disfruta actualmente Estocolmo gracias a las producciones escandinavas del género conocido como nordic noir que en los últimos años han creado potentes referentes audiovisuales. $^{3}$ Sin duda la producción argentina sigue el patrón establecido por el modelo nórdico de policiales televisivos negros en los que el crimen está relacionado con la corrupción política y el uso ilegítimo del poder, y donde los protagonistas se caracterizan por una moralidad ambigua. No menos importante, el thriller argentino se aprovecha de la espectacularidad de los majestuosos y exóticos panoramas que invitan al público global a visitar el país y a ver con sus propios ojos los lugares donde se filmaron las escenas, fomentando así el crecimiento del turismo internacional.

Sin embargo, aunque la serie argentina quiere ser asociada con la marca nordic noir y su estética exquisita, la razón explícita de la invocación de la capital de Suecia se revela en el octavo episodio cuando Isabel, una política poderosa y manipuladora, le pregunta sarcásticamente a su recién liberada hija Rosario si estaba justificando y defendiendo a uno de sus secuestradores, el Agente $\mathrm{H}$, porque sufría del síndrome de Estocolmo. Esta referencia cínica, junto con la segunda parte del título Identidad perdida, da cuenta de la subjetividad de la segunda década del siglo XXI que representa un síndrome de la experiencia de un pasado traumático constituido por la impunidad de los crímenes de la época de la dictadura cívico-militar (1976-1983) y la ineficacia del sistema judicial, aunque la trama principal de la serie gira alrededor de un referente globalizado, el tráfico y esclavitud de mujeres jóvenes con un toque de glamour salpicado de denuncia social.

A continuación me propongo analizar la serie argentina desde la perspectiva del género tomando en cuenta la asociación que los productores quieren establecer a través del prisma de la patología del síndrome de Estocolmo, puesto que en la jerga global mediática este implica la sumisión voluntaria de la víctima femenina al agresor masculino. De esta manera la serie provee al espectador un "amor perverso" que presupone la violación y esclavitud sexual perpetuando así

\footnotetext{
${ }^{1}$ La serie, producida por Story Lab y Kapow para Netflix, nunca llegó a emitirse en la TV argentina a pesar de haber ganado un concurso de INCAA.

2 Los subtítulos en español inclusive le quitan toda la "argentinidad" a las palabras de los protagonistas.

${ }^{3}$ Me refiero al brillante y sensible policía Wallander, el puente de Oresund que une y separa a Dinamarca y Suecia popularizado en Puente (Bron/Broen), la detective y madre soltera incapaz de reconciliar las demandas de su vida profesional y personal de la impresionante trilogía danesa Crónica de un asesinato, o los fascinantes y lúgubres paisajes de fiordos islandeses en la historia Atrapados.
} 
la dicotomía patriarcal que asocia lo masculino con la dominación y lo femenino con la sumisión. A la vez, mi ensayo se enfocará en la difuminación de los referentes y temas emblemáticos de la dictadura cívico-militar que fantasmalmente deambulan por el thriller argentino despolitizados y ajenos al ámbito sociopolítico. Esto se manifiesta en las numerosas escenas de secuestros, de madres portando pancartas con fotos de sus hijas desaparecidas, de mujeres encarceladas con ojos vendados, de investigaciones forenses, así como cuando se invocan los lemas de justicia, verdad y nunca más.

\section{EL SÍNDROME DE ESTOCOLMO EN LAS DISPUTAS POR LA MEMORIA}

El Diccionario de la Real Academia define síndrome como un "conjunto de síntomas característicos de una enfermedad o un estado determinado" en cuanto a su uso médico y en su acepción más general "como un conjunto de signos o fenómenos reveladores de una situación generalmente negativa." Mientras que el policial argentino Estocolmo: Identidad perdida juega con el concepto patológico de síndrome de Estocolmo como "trastorno emocional que se caracteriza por la justificación moral y el sentimiento de gratitud de un sujeto hacia otro de quien forzosa o patológicamente dependen sus posibilidades reales o imaginarias de supervivencia,"4 la serie misma simboliza un síndrome de la seducción de la perversión política, económica y social provocadas por la globalización neoliberal en Argentina y las particularidades de las políticas de la memoria (y olvido) que el neoliberalismo articula.

El síndrome de Estocolmo es un término acuñado en 1973 y hecho célebre con el famoso juicio de Patty Hearst en el marzo del 1976 --es decir, al mismo tiempo que en Argentina empezaba la dictadura cívico-militar --relacionado con el asalto a un banco de la capital sueca en el que una de las rehenes se resistió al rescate, defendió públicamente a su agresor y acabó comprometiéndose con él, dando así nombre a ese tipo de identificación psicopatológica en la cual una víctima de secuestro desarrolla una relación afectiva de dependencia hacia su secuestrador y termina adoptando sus creencias y motivaciones. ${ }^{5}$ Aunque ni la Asociación Americana de Psiquiatría ni la Organización Mundial de la Salud reconocen ni incluyen el síndrome de Estocolmo entre sus patologías, ${ }^{6}$ y su etiología es desconocida, es este el nombre con el que se ha venido designando al fenómeno psicopatológico de justificación moral, aceptación del sometimiento "voluntario" y sentimiento de gratitud que una persona detenida contra su propia voluntad y traumatizada desarrolla hacia su captor, de suerte que el secuestro del cuerpo desemboca en un secuestro de la voluntad (Montero Gómez, 3). Según las investigaciones de los psicólogos y criminólogos, a pesar de lo que puede sugerir la fascinación mediática,

\footnotetext{
${ }^{4}$ María Laura Quiñones Urquiza, “Consideraciones criminológicas sobre el síndrome de Estocolmo” Noticias jurídicas, 1/9/2008 [consultado 26/6/2017].

5 Paradójicamente, el caso sueco de 1973 no se corresponde con lo que la psicopatología denomina síndrome de Estocolmo, ya que se trataba de "atracción y enamoramiento" mientras que en el caso del síndrome ocurre una especie de secuestro de la voluntad de la víctima (Consultar Andrés Montero Gómez).

${ }^{6} \mathrm{Ni}$ el Manual Diagnóstico y Estadístico de los Trastornos Mentales ni la Clasificación Internacional de Enfermedades referencian el síndrome de Estocolmo.
} 
construida sobre numerosos ejemplos literarios y cinematográficos, ${ }^{7}$ el síndrome de Estocolmo no es un fenómeno común. ${ }^{8}$

Lo que caracteriza a los casos reales que dieron lugar a la acuñación del síndrome de Estocolmo más allá del suceso del año 1973 en la capital sueca, es que la situación se crea siempre en una víctima de sexo femenino a partir de la iniciativa masculina. Tal es el ejemplo de Patty Hearst, quien, habiendo sido secuestrada en 1974 por los militantes revolucionarios, y una vez pagado el rescate, permanece con el grupo y participa en sus acciones; o el de Natascha Kampusch quien desde su secuestro en 1996 pasó 3096 días en cautiverio forzada a mantener una relación íntima con su captor y a quien, después de dar a luz a dos hijas suyas, termina justificando. En el síndrome de Estocolmo la víctima de sexo femenino pierde su agencia, resignándose a aceptar las condiciones impuestas a través de las distintas tecnologías disciplinarias que le aplica el agresor. ${ }^{9}$ Es más, en este paradigma la mujer secuestrada desarrolla un sentimiento de empatía y agradecimiento hacia el agresor iniciándose así su dependencia respecto de él. La restitución de la identidad femenina se efectúa mediante la sumisión al agresor, haciéndose cómplice de él, lo que a la vez implica la traición a los valores sostenidos por la víctima antes de su privación de libertad. La relación entre víctima y victimario es asimétrica y refleja la relación de poder que vertebra el sistema patriarcal, asumiendo que el cerebro de la mujer necesita ser lavado de sus convicciones anteriores y prepararse para la inscripción apropiada que supondrá experimentar sentimientos positivos hacia el captor y compartir sus valores. Es una relación de dependencia emocional en la que la mujer víctima se supone pasivamente sometida al deseo y manipulación de un torturador sádico: una tabula rasa en espera de la inscripción de los nuevos

\footnotetext{
7 El ejemplo más conocido globalmente es la película El portero de noche de Liliana Cavani (1974) en relación a los campos de concentración nazi; en el ámbito chileno y en relación a la dictadura de Pinochet: El palacio de la risa de Germán Marín (1995), El desierto de Carlos Franz (2005), Carne de perra de Fátima Sime (2009), La vida doble de Arturo Fontaine (2010), la obra de teatro Medusa (2010) Ximena Carrera; y en Argentina: las obras de teatro Paso de dos de Eduardo Pavlovsky (1990) y Esa extraña forma de pasión, (2010) de Susana Torres, las novelas El fin de la historia de Liliana Heker (1996), La mujer en cuestión (2003) de María Teresa Andruetto y Noche de lobos de Abel Posse (2011); el cuento de Juan Martini “La colaboración” (2007), entre otras. Para el análisis del uso del síndrome de Estocolmo en las novelas chilenas consulte mis artículos: Ksenija Bilbija "Terapias literarias chilenas: justicia y reparación en $L a$ muerte y la doncella de Ariel Dorfman y El desierto de Carlos Franz" Donde no habite el olvido. Herencia y transmisión del testimonio en Chile. Ed. Emilia Perassi, Di-Segni de la Universidad de Milán. Italia, 2017. Pp. 111-126; Ksenija Bilbija "El síndrome de Estocolmo: ajuste de cuentas y otros saldos literarios en la ficción post-dictatorial chilena" in Poner el cuerpo: Rescatar y visibilizar la sexualidad y la violencia de género de los archivos dictatoriales del Cono Sur. Eds. Ksenija Bilbija, Ana Forcinito, Bernardita Llanos, Santiago de Chile: Cuarto Propio, 2017. Pp. 85-105;

8 El psicólogo Andrés Montero Gómez de la Universidad Autónoma de Madrid, quien propone una hipótesis etiológica para el síndrome de Estocolmo, sostiene que "su grado de incidencia en las víctimas no es tan habitual como popularmente se pueda suponer" (20). Los datos del FBI sobre secuestros y toma de rehenes, confirman que el 95\% de las víctimas no sintieron ningún síntoma del síndrome de Estocolmo (Fuselier, 23). Emilio Meluk, psicólogo y profesor colombiano de la Universidad Nacional, concluyó que en Colombia el síndrome de Estocolmo no ocurre después de analizar 280 secuestros de la época del boom de los secuestros entre finales de los 90 y principios de los 2000.

${ }^{9}$ En Historia de la sexualidad, Michel Foucault propone que la sexualidad es un capital que la sociedad moderna inscribió en la economía del placer y en el régimen de poder. "El dispositivo de sexualidad tiene como razón de ser el hecho de proliferar, innovar, anexar, inventar, penetrar los cuerpos de manera cada vez más detallada y controlar la población de un modo más global" (Foucault, 1991:103).
} 
valores. ${ }^{10} \mathrm{La}$ dependencia de la víctima puede extenderse más allá de su liberación, pero la sobreviviente acaba dejando de reconocer el poder del agresor. ${ }^{11}$

El contexto de la dictadura argentina y el secuestro de los súbditos ${ }^{12}$ es muy distinto del de los casos que dieron fama global al síndrome de Estocolmo. Mientras que los rehenes suecos, por ejemplo, declararon repetidamente que se sentían más seguros con sus captores que con la policía --incluyendo al mismo primer ministro del país, Olof Palme, con quien estaban en comunicación-- porque temían un ataque en el que podían perder la vida como un daño colateral, en Argentina, sin embargo, tal distinción no existía: el Estado era el secuestrador ilegal protegido por el presidente, el general Videla. ${ }^{13}$ Asimismo, en tanto que en el caso sueco los rehenes desarrollaron sentimientos positivos hacia los captores, quienes además de tratarlos bien eran vistos como una especie de justicieros solitarios, de Robin Hood contemporáneos, puesto que robaban un banco y no a la gente, en Argentina la tortura de los detenidos desaparecidos era institucionalizada.

Desde el 2007, cuando se reabrieron las causas judiciales por delitos de lesa humanidad perpetrados en el centro clandestino de la Escuela Mecánica de la Armada (ESMA) conocidas como Mega Causa ESMA, los defensores de los funcionarios del Estado acusados intentaron argumentar diferentes grados de complicidad y responsabilidad de las mujeres violadas y sexualmente acosadas para ocultar los crímenes de la dictadura y obtener la impunidad de los imputados. Por eso, en el fallo del segundo tramo de la Mega Causa ESMA, después de citar extensamente varias investigaciones del ámbito de la psiquiatría, la psicología, la jurisprudencia, la criminología y la sociología sobre el síndrome de Estocolmo, el tribunal concluye que "el comportamiento de las víctimas aludido por los imputados al inicio, respondía 'básicamente' a una situación de coacción constante de la cual dependía su vida" (358-9).14 A lo largo de más de cuarenta páginas dedicadas a las explicaciones sobre el síndrome de Estocolmo, los miembros del tribunal dan evidentes muestras de incomodidad a la hora de usar el término (por miedo quizá a que su uso pueda ser interpretado como un aval, prefiriendo expresiones del tipo "tendrá que ver con un estímulo estresante externo," calificándolo con el adjetivo "denominado" ("denominado síndrome de Estocolmo" p. 327) y entrecomillándolo ("Estocolmo” (326)), indicando de esta manera su cautela, evitando comprometerse con el uso de un término que no estaba unánimemente aceptado por la comunidad científica. Asimismo, sugerían que el reconocimiento del síndrome de Estocolmo servía para culpabilizar a las víctimas que supuestamente actuaron como "participantes voluntarias" de su propia situación y que se beneficiaron de ella. En otras

10 Lo más cercano en la mitología griega a la relación descrita por el síndrome de Estocolmo es el secuestro/ abducción de la ninfa Perséfone, hija de Zeus y Deméter por Hades, el dios del infierno. Aunque al principio se niega a comunicarse con el raptor, finalmente come de la granada, lo que la ata para siempre con su raptor, así que sus padres llegan a un acuerdo con el dios del infierno quien acepta dejarla pasar la mitad del tiempo en la tierra y otra mitad con él.

11 Claudia Card, "Women, Evil and Gray Zones” Metaphilosophy, Vol. 31. No. 5, October 2000. p. 510. PRINT

12 El término "súbdito" parece más apropiado que "ciudadano" porque en una dictadura los derechos de la ciudadanía no se reconocen como en un Estado de derecho.

13 Ehnmark [una de las secuestradas suecas] le dijo al presidente: "Confío plenamente en Clark [secuestrador] y el ladrón. No estoy desesperada. No nos han hecho nada, al contrario, han sido muy buenos. Pero sabes algo, Olof, a lo que le temo es a un ataque policial que nos cause la muerte".

14 A continuación, adjuntamos el enlace. 
palabras, los miembros del tribunal veían el intento de los defensores de los funcionarios del Estado de usar la óptica del síndrome de Estocolmo como la victimización adicional de las mujeres secuestradas. Los autores del fallo parecen indicar que el reconocimiento de la validez del síndrome de Estocolmo, bajo el que algunas mujeres llegaban a mantener relaciones íntimas con su raptor, implicaría transformar a la víctima en cómplice y consecuentemente no ayudaría a explicar satisfactoriamente los crímenes de lesa humanidad cometidos en los centros clandestinos de tortura ya que los oficiales no sólo eran responsables de secuestrar, violar, maltratar y detener ilegalmente a una persona, sino también por los daños psicológicos causados a las víctimas.

Vivimos en una sociedad del espectáculo en la que el potente poder mediático del síndrome de Estocolmo reside en electrizar la intersección entre el sexo y la violencia con la visión de servidumbre voluntaria de la mujer que consiente y goza de su privación de libertad. Unos años después de la dictadura cívico-militar, el 14 de marzo del 1998, la revista Noticias publicó el reportaje titulado "Amores clandestinos" sobre las relaciones íntimas dentro de la ESMA, contribuyendo así a la fascinación popular con la idea de que el amor puede surgir en cualquier ambiente, inclusive "al pie de la mesa de flagelo" (24). Una de las co-autoras, la periodista Olga Wornat, que durante la dictadura vivió en la clandestinidad, reconoce su propio error en cuanto a creer "equivocadamente, durante mucho tiempo, que no era imposible que una mujer se 'enamorara' de su secuestrador o al revés" (35). Dieciséis años después, en Putas y guerrilleras, libro sobre los crímenes sexuales en los centros clandestinos de detención que Wornat escribió con Miriam Lewin, la periodista rectificará su equívoco: "Mientras pasaron los años y me comprometía más y más con estas historias, dejé de creer que estas relaciones eran 'amores perversos' o 'un síndrome de Estocolmo,' para asumir con total convicción que son crímenes aberrantes, delitos de lesa humanidad, y que había estado equivocada durante largos años" (74). Su cambio de perspectiva coincide con las investigaciones del psicólogo colombiano Emilio Meluk, quien, al revisar un gran número de secuestros en su país sin encontrar ningún caso de síndrome de Estocolmo, sostiene que "el término es obsoleto debido a que la forma de supervivencia de un secuestrado, en un momento dado, es inclinarse a favor de los secuestradores." 15

En la jerga global mediática el síndrome de Estocolmo ha llegado a denotar un "amor perverso." Propone una psicología que implica la fascinación no sólo con la violencia y el sexo, sino también con la violación y esclavitud sexual. Supone el placer de una mujer que se transforma en cómplice de una relación constituida por la dependencia afectiva y el sufrimiento. Construye la imagen de la mujer como un ser capaz de disfrutar de la violación sexual bajo tortura y crea el supuesto erotismo que proviene de la visión de la mujer desnuda, engrillada y encapuchada. En otras palabras: una mujer despojada de ropa, expuesta a la vista, pero sin poder ver, atada y sometida a la voluntad del otro. En el consumo mediático tal representación del cuerpo femenino reescribe la dicotomía patriarcal: masculino/dominación y femenino/sumisión.

La fascinación con el sexo empaquetado y envuelto en los perversos y seductores pliegues del síndrome de Estocolmo, es sólo una de las herencias de la dictadura que el policial argentino proporciona a los espectadores globales. Los temas de la búsqueda de la verdad, de la justicia, de

15 A continuación, adjuntamos el enlace. 
la memoria y de la identidad (anunciada de antemano como perdida) rondan fantasmalmente la serie televisiva, aunque despolitizados y despojados del ropaje de corte sociopolítico y aún menos de contenido histórico. Por otra parte, aunque la trata de personas es un problema actual, el relato y la visión que ofrece Estocolmo: Identidad perdida no ha seducido a los telespectadores globales de Netflix que después de 7 meses le dieron una valoración bastante mediocre, de 6.2/10 (filmaffinity le da aún menos, 4.7/10). Ya no se menciona la posibilidad de una segunda temporada y parece que los productores de la serie no podrán cobrar los dividendos imaginados puesto que lo único que han conseguido es frustrar a sus consumidores: según uno de los reseñadores anónimos, estaba como si padeciera el síndrome de Estocolmo por aguantar 9 de 13 episodios. ${ }^{16}$

\section{EL PROTAGONISMO FEMENINO DE ESTOCOLMO: IDENTIDAD PERDIDA EN EL ESCENARIO NEOLIBERAL}

Aunque narrativamente pobre y psicológicamente poco convincente, sin verdadero suspenso y más parecido a un culebrón que a un thriller de calidad del ámbito de nordic noir, la trama de Estocolmo: Identidad perdida sigue la investigación periodística y policial de una red de trata de mujeres, iniciada por la desaparición emblemática de la bella Larissa Torres. La serie está ambientada en Buenos Aires y en Villa La Angostura, cuyos majestuosos lagos y bosques contrastan con la urbe porteña y sus imponentes torres que alojan las modernas oficinas de cristal relumbrante y acero en las que se mueven los personajes. Los protagonistas principales son la periodista Rosario Santa Cruz, seria, honesta y dedicada a su profesión, hija de la diputada de un partido conservador y del padre propietario del mismo canal de noticias donde ella trabaja. En un momento empezará a tener dudas en cuanto a su propia identidad y descubrirá que su madre biológica es Teresa, la misma líder de la red internacional VIP de trata de blancas, quien había sido vendida por su padre por dinero y tuvo a Rosario con uno de sus clientes (Alfredo Santa Cruz) quien se quedó luego con el cuidado de la hija. Otro protagonista es el fiscal Franco Bernal, un seductor perverso, atractivo, ambicioso y oportunista con gusto por el sexo sádico, quien investiga la trata de mujeres y los feminicidios. Termina siendo candidato a la vicepresidencia de la nación junto con la madre adoptiva de Rosario como candidata a la presidencia, moviéndose sin escrúpulos entre ambos lados de la ley. Finalmente, el tercer protagonista es Gonzalo, el infiltrado Agente $\mathrm{H}$, introducido por el propio fiscal, quien ha matado y secuestrado a varias personas para mantener su identidad encubierta. Gonzalo es medio hermano del fiscal, lo que proporciona otra relación familiar conflictiva. Entre Rosario, Gonzalo y Franco surge un triángulo amoroso que termina con el noviazgo entre el fiscal y la periodista a pesar de que ella tiene un hijo con el Agente H. La trama bascula entre dos líneas temporales que resultarán en un montaje paralelo entre el año 2015 (la actualidad) y el 2012, cuando Rosario decide sacar en limpio el caso de la joven Larissa estancado en la fiscalía desde hace un año. Su determinación de investigar el caso que el sistema legal y la justicia argentina parecen haber abandonado es lo que eventualmente acabará provocando el secuestro y la desaparición de la propia periodista. La segunda historia que corre paralela a la principal se

\footnotetext{
16 "Síndrome de Estocolmo es el que debemos de sufrir los espectadores. Si no, no se entiende que hayamos aguantado nueve capítulos. Además de no entender la mitad de los diálogos, la trama, con el discurrir de la historia, cada vez se hace más incomprensible. Así pues, aquí la dejo. Infumable.” A continuación, adjuntamos el enlace.
} 
desenvuelve alrededor del médico forense quien desde la morgue determina las causas de los feminicidios que investiga el fiscal y quien resulta ser un asesino en serie que desde 1980 ha matado a 74 mujeres, dejando en todas ellas su marca en forma de un número tatuado en el antebrazo. Además, el forense había entrenado a su alumno "más promisorio" a continuar su labor feminicida. Este alumno es un psicópata a quien los espectadores vemos elegir, secuestrar y asesinar a sus víctimas a lo largo de la serie y quien resulta ser una reconocida autoridad sobre la historia y la práctica del tatuaje. Este segundo hilo narrativo que tiene una conexión bastante borrosa con la trata de mujeres, el tema explorado en la historia principal, es donde aparece una vaga referencia a la dictadura que Argentina sufrió entre el 1976-1983.

El síndrome de Estocolmo invocado en la serie está situado en el escenario del capitalismo neoliberal que reconoce los logros del feminismo y lo declara obsoleto, puesto que (supuestamente) la opresión femenina es ya parte del pasado. ${ }^{17} \mathrm{El}$ credo neoliberal ha consensuado la independencia económica, profesional y sexual de la mujer pero no sin adaptar estas valencias a la economía de libre mercado cuyo sistema de valores le asigna la agencia a la mujer a través de la explotación de su sexualidad. El mercado remunera y empodera, pero no es ciego en cuanto al sexo. En Estocolmo: Identidad perdida los personajes femeninos disfrutan de los beneficios logrados por el feminismo ya que son mujeres emancipadas, decididas, con profesiones lucrativas y aparentemente dueñas de su sexualidad, pero su deseo existe en función del hombre y no les pertenece a ellas mismas. ${ }^{18}$ Las mujeres mayores, las que ya han roto "el techo de cristal" y han alcanzado el imperativo del empoderamiento femenino asumido por el modelo neoliberal --tanto la madre biológica como la madre adoptiva de Rosario --nunca están en relaciones o escenas con connotación sexual aunque ambas de jóvenes trabajaban con sus cuerpos: la diputada era modelo y la líder de trata VIP era prostituta. Las mujeres jóvenes tampoco parecen disfrutar de su sexualidad y la exhiben para conseguir el poder que está en el varón. Aparecen atractivas, pero no son tan seductoras como los hombres. ${ }^{19}$

En la diégesis de la serie, la joven periodista Rosario está en una relación gobernada por la dependencia emocional y psicológica no sólo de su prometido, el fiscal Bernal, sino también del Agente H. Las primeras palabras de la serie, cuando el espectador no sabe con certeza qué implica la palabra Estocolmo del título, son la súplica "Cuídame," que Rosario le dirige al fiscal, a la que él contesta "Te amo" mientras le agarra fuertemente de la mano dirigiéndose hacia el estudio del canal $24 / 7 \mathrm{~N}$, donde serán entrevistados como "la pareja del momento." Poco después ella va a exhibir un comportamiento un tanto extraño y aparentemente sin sentido, cuando frente a las cámaras saca la pistola, apunta y dispara a los camarógrafos porque acaba de

\footnotetext{
17 Para una excelente discusión sobre el feminismo y neoliberalismo en América Latina ver el artículo de Verónica Schild, "Feminismo y neoliberalismo en América Latina" Nueva Sociedad, 265, Septiembre-Octubre 2016.

18 Un buen ejemplo de esta dependencia del deseo sexual del varón aparece hacia el final del segundo episodio cuando Chloe, una alumna del fiscal Bernal se jacta de sus numerosos encuentros sexuales y le menciona a su amiga que acaba de pasar una noche con mismo fiscal y otra mujer (jmuy famosa y cara aparentemente!) que el fiscal le había ordenado proporcionar y organizar. Pronto después de la conversación será secuestrada y asesinada por el psicópata tatuador. (1, 21.15 y 2, 36.32)

19 Ambas Isabel y Teresa tienen algo de monstruoso: a Isabel, antes de aparecer en el noticiero por primera vez, la enfocan por detrás y en el espejo donde iluminan su cuello enjoyado y la peluca que se pone en el momento y Teresa, además de escoger una vida sin su propia hija de la que voluntariamente se separa, se ha enriquecido y empoderado gracias a la labor de otras mujeres forzadas a trabajar para ella como prostitutas.
} 
recibir un mensaje perturbador del Agente $\mathrm{H}$ en el que anunciaba ominosamente que estaba tan cerca de ella que podía oler su perfume. La escena inaugural de la serie crea la impresión de que Rosario no es dueña de sus actos y nos traslada a una secuencia "tres años antes" donde se origina la historia de la dependencia de Rosario que nos dará la clave de su aparente trastorno. El comienzo del tercer episodio es aún más explícito en cuanto a la dependencia psicopatológica de Rosario cuando está en la cama con el fiscal quien le dice que es la esclava de él y del Agente H, y le reitera que tiene que hacer lo que él, su prometido, le diga. Anticipándose a la posible confusión de los espectadores acerca de lo que en ese momento están viendo, él verbalizará esta duda en una pregunta retórica: "Lo que no entiendo es ¿por qué seguís queriendo que yo sea tu dueño?" seguida por una paliza que le da antes de añadir: "Porque eres una puta, fuiste la puta de él y bien puta con él fuiste, y ahora yo te hago sentir una puta con poder. ¿Y a quién no le gusta el poder? ¿No? Pero lamentablemente eso sólo te lo puedo dar yo. Soy tu dueño Rosario" (3, 1.3-2.08). En el octavo episodio la madre adoptiva de Rosario verbalizará el diagnóstico y le dará el nombre exacto al aparente trastorno de la hija: el síndrome de Estocolmo.

La trama de la serie parece insinuar que una mujer, sea una periodista investigadora como en el caso de Rosario, o cualquier mujer con una profesión pública, tiene entrada a la esfera de los hombres públicos sólo y literalmente como una mujer pública, una prostituta. La sexualidad de Rosario está vista como una mercancía (eres una puta) cuyo valor añadido viene de su relación de pareja con el fiscal. Este empoderamiento adicional de una simple puta está representado en varios personajes femeninos de la serie, empezando con la madre biológica de Rosario quien, habiendo sido vendida por su padre y empujada a la prostitución de joven, consigue alcanzar la posición de líder de la organización de trata de mujeres VIP, o Larissa Torres quien parece haberse resignado a la prostitución después de un proceso de disciplinamiento ejercido por sus secuestradores. $^{20}$ Dentro del mundo laboral de Estocolmo: Identidad perdida una mayoría abrumadora de protagonistas son mujeres que se aprovechan de las opciones que les brinda la sociedad de consumo. ${ }^{21}$ Muchas de ellas tienen diferentes cargos en la producción del programa televisivo o son detectives que investigan los crímenes y todas disfrutan efusivamente de su sexualidad sin arredrarse a la hora de proponerles sexo a los hombres. Aunque la serie parece crear una imagen de la mujer triunfadora en la sociedad, es precisamente el ámbito laboral--el que debería ser el trampolín de su liberación-- lo que las atrapa y acaba convirtiéndolas en víctimas de secuestros y asesinatos que terminan con el tatuaje del código de barras en su cuerpo. Aquello que prometía el desarrollo pleno de sus capacidades como personas acaba transformando a estas mujeres en la más cosificada de las mercancías. Y como la otra vertiente de la serie es la trata de mujeres, el espectador global de Netflix se enfrenta con el mundo en el que el hombre todavía controla la vida de las mujeres y donde el trabajo fuera de casa implica o la muerte o la prostitución. Parece que explotar sexualmente a la mujer es uno de los mayores negocios del modelo económico neoliberal.

\footnotetext{
20 Las teóricas latinoamericanas han llamado la atención sobre la resignificación de la autonomía de la mujer demandada por el feminismo de los años sesenta en el empoderamiento en el contexto neoliberal.

21 A diferencia de la serie argentina, el auténtico nordic noir tiene como protagonistas fuertes personajes femeninos, generalmente sin tacones altos ni vestidas a la moda, pero intuitivas, eficaces y bastante inquietantes (la jefa de homicidios Sarah Lund en Crónica de un asesinato) y complementarias con los protagonistas masculinos (por ejemplo Saga y Martin de Puente).
} 


\section{LA VIOLENCIA DE ESTADO DIFUMINADA}

Dentro del marco del anunciado síndrome de Estocolmo que afecta a la protagonista principal, aparecen numerosas escenas de secuestros, de madres desesperadas que llevan pancartas con fotos de sus hijas desaparecidas, de víctimas encapuchadas y engrilladas en sótanos mugrientos, de mujeres encarceladas que a veces los secuestradores sacan a restaurantes para comer en público, de hijos que imploran saber la verdad en cuanto a su procedencia e identidad, de invocaciones del "nunca más" y de investigaciones forenses. La lista bien podría pertenecer a un inventario de imágenes emblemáticas de los años de plomo, y, sin embargo, Estocolmo: Identidad perdida disloca y difumina los signos del terrorismo de Estado sin llegar a borrarlos del todo. El único momento en el que se evoca la dictadura explícitamente se da en el tercer episodio cuando el médico forense decide darle una pista al fiscal y le entrega los archivos del año 1980 explicando que "Hace 35 años encontramos una serie de cuerpos femeninos con tatuajes parecidos y con el mismo número que tiene el cuerpo que encontramos. Como era la época de los milicos y estos hijos de puta hacían lo que querían, nunca supimos si el asesino era un uniformado o era un loquito cualquiera, común y corriente. Nunca supimos nada" (3, 9. 35-9. 38). ${ }^{22}$ El gesto del forense es narcisista y refleja su sentimiento de superioridad sobre el fiscal porque en el último episodio se revelará que él era el asesino serial quien después entrenó a un discípulo para que continuara su magnum opus psicópata. El mismo número tatuado está ahora actualizado en el formato del código de barras implicando mayor sofisticación y mejor nivel de producción de los feminicidios. Al mostrar el cuerpo femenino con el código de barras se lo identifica con un artículo comercial estandarizado que sugiere que en la epistemología neoliberal la mujer es el producto de consumo. Aunque el tema principal de Estocolmo: Identidad perdida es la trata de mujeres e introducir el código de barras enfatizaría su identidad como objeto de consumo, la trama secundaria en la que aparece el tatuaje del código en los cuerpos femeninos está relacionada con los feminicidios que investiga el fiscal y nunca se relaciona con los casos de trata de mujeres. La confesión final del forense revelaría su convicción de que el ser humano es por naturaleza depredador y cazador y que por eso "yo mato, aniquilo y consumo el último soplo de aire de mis víctimas. Hasta hoy maté 74 mujeres. Y en todas dejé mi marca" (13, 28.04-28.32). La alusión a la dictadura se revela como una pista falsa ya que el asesino era, si no "un loquito cualquiera, común y corriente" un psicópata cuya labor continuará con su alumno a quien el espectador ya vio ejercer el legado del forense. 23 Sin embargo, esta tenue conexión con la dictadura sí es un eslabón relevante porque evoca la impunidad de los crímenes cometidos en aquella época, hace 35 años, y los identifica como el patrimonio del régimen militar. La etimología de la palabra "forense" remonta a la esfera del "fórum" y como tal invoca un espacio público en el que gracias a la pericia del médico forense se determina la causa de la muerte para

\footnotetext{
22 En el episodio 12 (9.9 min) uno de los policías le cuenta al detenido psicópata tatuador que su abuela era una de las víctimas en "la época del miedo" y que apareció con el mismo número tatuado y que él se va a vengar.

${ }^{23}$ El testamento y la confesión que imprime en la morgue y deja para la posteridad, mientras está brindando con su alumno, indica sus creencias con más detalle: "El hombre caza al hombre porque en definitiva el animal caza al animal y nosotros somos la vanguardia de esa realidad. No existe sofisticación. Existe la tinta que perdura sobre el cuerpo ya sin vida. Existe el hedor del cuerpo putrefacto y, sobre todo, la certeza para todos nosotros quienes convivimos con esta sensación carnal del existir que nuestra tarea es necesaria, poderosa y eternamente inconclusa." (13, 29.10-29.50)
} 
los tribunales de justicia. Aunque la psicopatía del médico forense que protagoniza la teleserie había comenzado durante la época del terrorismo de Estado y sus crímenes se podrían ver como inferencia y derivación de una violencia deshumanizadora, la conexión es rechazada, desapareciendo a la vez la oportunidad de algún tipo de una imaginaria justicia reparadora que Estocolmo: Identidad perdida podía haber ejercido. No obstante, la teleserie negra argentina no es tal post mortem del pasado dictatorial ni provee léxico para articular las injusticias cometidas por el régimen autoritario.

El derecho a la vida y a la identidad, dos conceptos clave mantenidos por las organizaciones de los derechos humanos dedicadas a los crímenes de lesa humanidad cometidos por la dictadura cívico-militar argentina, han sido despojados del significado histórico y reemplazados con los individuos que actúan como buenos o como malos (o como psicópatas), pero no pertenecen a ninguna estructura ideológica ni comparten utopías (que no sean psicopáticas). El Estado terrorista se sustituye por el terrorismo de una organización criminal de trata de mujeres, la figura del detenido desaparecido es reemplazada con la de una mujer secuestrada y forzada a la esclavitud sexual, y el trabajo del equipo argentino de antropología forense que se dedicaba a la identificación de los restos de cadáveres $(\mathrm{NN})$ ha sido reemplazado por la infatuación de un perturbado médico forense feminicida. De esta manera, el thriller argentino desvía y desplaza la reclamación histórica de restitución de las identidades perdidas en la dictadura con una mediatización de la aparente búsqueda de verdad y justicia que, siempre evasivas y escurridizas en el escenario neoliberal, ni pueden ser ubicadas ni catalizadas en acción. Lo que daría para una segunda, tercera o cuarta temporada de la serie.

La trama de la serie gira alrededor de los conceptos de la verdad, la ley y la justicia. Se supone que el fiscal Franco Bernal representa la ley mientras que Gonzalo es el justiciero solitario. Crecieron juntos, así que son como hermanos dado que sus padres ya los tenían cuando se enamoraron, están unidos emocionalmente, se conocen bien, pero se enemistan y terminan siendo adversarios. Aunque la justicia es una reparación social administrada por un organismo legítimo y como tal debería ser asumida por el fiscal, Estocolmo: Identidad perdida, separa los conceptos de ley y justicia desde el principio. En el segundo episodio Rosario le dice a Gonzalo "A mí lo que me importa es la verdad. En este país la ley no protege a las víctimas. Así que hay que armar una especie de justicia propia para darle un poco de paz a esta madre." Gonzalo le contesta: "La ley y la justicia son dos cosas distintas" (15.33), estableciéndose como alguien que va a reparar las insuficiencias de la ley encargándose de la administración de la justicia. La trama del hilo narrativo paralelo sobre el psicópata tatuador también invoca el concepto de justicia en un ambiente corrupto. Por ejemplo, en una escena cuando tiene a su secuestrada víctima de turno, ya tatuada, bañada y vestida con la ropa que él le había escogido, le lee con tranquilidad los fragmentos de la novela naturalista catalana La puñalada (1903-4) de María Vayreda, destacando especialmente "el ambiente de corrupción en el que vivían, aquél le era favorable pues era el suyo propio y dentro de él triunfaba la superioridad de su ingenio, de su despreocupación y de su 
fuerza corporal" $(6,40.28) .{ }^{24}$ La misma novela, como un intertexto referencial, resulta ser también la lectura favorita y frecuentemente citada por el médico forense quien resalta el ambiente de corrupción e inseguridad jurídica como propicios para su labor feminicida desde los años de la dictadura.

La implementación de la justicia en Argentina ha tenido sus idas y vueltas de una pauta inestable ya que los delitos de la dictadura se juzgaron a pesar de las leyes de Punto Final y Obediencia Debida durante el Juicio a las Juntas Militares en 1985, pero ya en 1989 y 1990 el presidente Menem había indultado a los juzgados. En 2003 se abrieron las causas por el robo de los bebés y los indultos fueron declarados inconstitucionales por la Corte Suprema, pero la justicia sigue dando tumbos. Muy recientemente, el 3 de mayo del 2017, se aplicó la Ley 24390, llamada Ley 2x1 y ya derogada en 2001 a un represor convicto, estipulando que "si un preso pasara más de dos años en prisión preventiva sin condena firme, por cada día de reclusión se le computarían dos" dejándolo efectivamente en libertad. ${ }^{25}$ La cultura de la impunidad y la falta de confianza en las instituciones públicas, junto al déficit de verdad y de justicia, parece ser un síntoma más del síndrome que permea el cuerpo de la serie y que refleja la subjetividad argentina de la segunda década del tercer milenio. 26

Uno de los referentes más prominentes de la lucha por los derechos humanos en Argentina son las Madres de la Plaza de Mayo, el grupo que en 1977 inició su marcha por la histórica plaza exigiendo la aparición con vida de sus hijos. Desde el primer episodio de Estocolmo: Identidad perdida se le da espacio visual a las madres que buscan a sus hijas desaparecidas. A diferencia de la época dictatorial cuando buscaban a sus hijos en las comisarías, ahora van a las oficinas del canal 24/7 de noticias en vivo que parece haber sustituido al Estado en su tarea de investigación de crímenes convirtiéndose en el brazo de una justicia independiente que alcanzará a los transgresores de la ley. La Plaza de Mayo como espacio público y político en el que las Madres empezaron su marcha ha dado paso al estudio del noticiero y a la pantalla televisiva. Lo que no ha cambiado desde la dictadura es que las madres tienen que esperar para reclamar. Ahora, en los estudios del programa televisivo sus plegarias se transformarán en sound bites editados y reducidos a los inofensivos eslóganes retóricos "exigimos justicia ya" (4, 25.47) y "nunca más" mientras esperan la señal del productor para levantar sus pancartas con las fotos de las hijas desaparecidas. La acción política que antes ejercían sus demandas es ahora parte del espectáculo mediático que no está interesado en el protagonismo colectivo y político de las madres-aunque la imagen televisiva revela más que a una madre afectada por la pérdida de su hija—sino en la carga emocional individual. El primer plano de la madre conmovida y desesperada (“Acá estamos

\footnotetext{
24 Según Francisco Rivas en esta novela aparece la situación del síndrome de Estocolmo unos setenta años antes del atraco al banco sueco: "El tema dominante en la novela mencionada es el efecto psicológico que sufren los habitantes de una región azolada por los malhechores; más, sin embargo, los mismo sufrientes les brindaban protección para que alcanzaran la impunidad. La figura del bandolero heroico es un personaje símbolo en el transcurso de la novela. Aquí encontramos el antecedente más remoto de lo que en 1973 se identificó como el síndrome de Estocolmo. Un asaltante de banco decidió tomar como rehenes a tres mujeres y un hombre, quienes a pesar de su doloroso cautiverio terminaron protegiendo a su raptor."

25 Artículo: "Argentina y la ley del 2x1: "Un fallo insoportable para las víctimas"”.

26 De acuerdo al World Justice Project, Argentina está en la posición 51 en el ranking mundial del Estado del Derecho que analiza a 113 países. En la categoría que analiza la impunidad en los casos de corrupción política, el país quedó en el puesto 68 , con un promedio de 0,47 sobre uno.
} 
presenciando el dolor de una madre" resume el titular de noticias), dirigido a los televidentes, sustituye la realidad del mensaje de su búsqueda de las hijas desaparecidas. Las emociones de las madres son un capital que revierte en el rating del programa televisivo, lo que lleva a mayores ingresos empresariales. Aún más, la televisión en vivo no sólo ha asumido el papel de intermediario que visibiliza las reclamaciones de las madres, sino que les ha quitado el protagonismo colectivo espectacularizando el trauma individual. El problema es que su "compromiso" con la causa de trata de mujeres está determinado por la duración de la atención de los espectadores y su identificación emocional traducida en el rating. En otras palabras, se trata de una atención efímera y un compromiso que no tiene futuro porque pronto vendrá otra catástrofe necesaria para evitar la fatiga emocional del telespectador. No hay duda de que Estocolmo: Identidad perdida critica la mercantilización del dolor a través de sus representaciones y revelaciones en cuanto a cómo se produce la narrativa del dolor y del espanto desde los bastidores del estudio televisivo, pero su apropiación de los referentes históricos sólo sirve para espectacularizar el sufrimiento.

La identidad perdida invocada en el título de la serie es otra secuela de la dictadura cívico militar argentina aunque este referente histórico está sistemáticamente silenciado en la retórica de la serie. En homenaje a la labor de las Abuelas de la Plaza de Mayo para encontrar a los nietos desaparecidos y apropiados por la dictadura, cada 22 de octubre se celebra en Argentina el Día Nacional por el Derecho a la Identidad. Aún más, gracias a su lucha se han incorporado a la Convención sobre los Derechos del Niño, los artículos 7, 8 y 11 que garantizan el derecho a la identidad, conocidos como artículos argentinos. La misión de las Abuelas ha sido restituir la identidad, y así no permitir el olvido. En la narrativa que se desenvuelve en Estocolmo: Identidad perdida, Rosario sostiene que "todos tenemos derecho de saber quiénes son nuestros padres. Aunque sean delincuentes” $(12,18.59)$. Su posición contrasta con la de una de las monjas que sirvieron de mediadoras en el traspaso del bebé entre la madre biológica y su nueva familia, quien tranquiliza al padre de Rosario por haberle escondido su verdadera identidad a su hija con estas palabras: "El pasado nunca se puede reparar. Es mejor construir un futuro. Un bello futuro" (13, 14.18). El alegato de la monja queda resonando en el silencio unos instantes y luego el escenario cambia. Estas dos actitudes frente al pasado traumático, una que lucha por recordar y reparar y la otra que aboga por el olvido en áreas del bienestar colectivo, reflejan el estado de la política de la memoria en la Argentina de la segunda década del siglo XXI.

La serie Estocolmo: Identidad perdida es una producción cultural que manipula y se apropia del trauma que aun perdura en la sociedad argentina desde la represión ejercida de la dictadura. Lo hace a través del uso de los símbolos asociados con la memoria histórica argentina, difuminando y borrando los referentes originarios y asignándoles nuevos significados personalizados y privatizados, en consonancia con las políticas neoliberales imperantes. Nuestra visión del pasado está determinada por nuestro presente que lo reelabora y reformula constantemente ya que "la verdad de la memoria no radica tanto en la exactitud de los hechos (res factae) como en el relato y la interpretación de ellos (res fictae)" (Lechner y Guell 18). ${ }^{27}$ La imagen de la realidad que produce

\footnotetext{
27 Lechner y Guell han articulado esta relación en su ensayo "Construcción social de las memorias en la transición chilena" Subjetividad y figuras de la memoria Eds: Elizabeth Jelín y Susana Kaufman, Buenos Aires: Siglo XXI. 2006, pp. $17-46$.
} 
la serie a través del reciclaje mudo de los referentes históricos de la época del terrorismo de Estado apunta hacia una sociedad que no ha conseguido sanar las secuelas de la impunidad fomentadas por el neoliberalismo y su "banalización de la memoria."28 La serie Estocolmo: Identidad perdida fracasa a la hora de lograr un auténtico thriller noir pero lo que logra es, quizás a su pesar, la transformación de la impunidad y la violencia contra las mujeres en auténtica marca Argentina.

${ }^{28}$ La consulta puede realizarse en el siguiente enlace. 


\section{BIBLIOGRAFÍA}

BilBIJA, Ksenija (2017). "El síndrome de Estocolmo: ajuste de cuentas y otros saldos literarios en la ficción post-dictatorial chilena”. BILBIJA, Ksenija, FORCINITO, Ana y LLANOS, Bernardita (eds.). Poner el cuerpo: Rescatar y visibilizar la sexualidad y la violencia de género de los archivos dictatoriales del Cono Sur. Santiago de Chile: Cuarto Propio: 85-105.

BILBIJA, Ksenija (2017). "Terapias literarias chilenas: justicia y reparación en La muerte y la doncella de Ariel Dorfman y El desierto de Carlos Franz." PERASSI, Emilia (ed.). Donde no habite el olvido. Herencia y transmisión del testimonio en Chile. Milán: Di-Segni de la Universidad de Milán: 111-126

Bourdieu, Pierre (2000). La dominación masculina. Barcelona: Anagrama. Impreso.

Calveiro, Pilar (2001). Poder y desaparición: Los campos de concentración en Argentina. Buenos Aires: Colihue.

CARD, Claudia. "Women, Evil and Gray Zones” Metaphilosophy, Vol. 31.5 (2000): 509-528.

CORPORACIÓN NACIONAL DE REPARACIÓN Y RECONCILIACIÓN (1996), Informe sobre calificación de víctimas de violaciones de derechos bumanos y de la violencia política. Santiago de Chile. [Consulta: 05/09/2016)

FOuCAulT, Michel (1991). Historia de la sexualidad. Buenos Aires: Siglo XXI Argentina Editores.

Fuselier, G. Dwayne. "Placing the Stockholm Syndrome in Perspective". FBI Law Enforcement Bulletin. Vol. 68. 7 (julio 1999): 22-25.

JELÍN, Elizabeth (2002). Los trabajos de la memoria. Buenos Aires: Siglo XXI.

LACAPRA, Dominick (2001). Writing History, Writing Trauma. Baltimore: Johns Hopkins UP.

LECHNER, Norbert y GÜELL, Pedro (2006). "Construcción social de las memorias en la transición chilena" JELÍN, Elizabeth y KAUFMAN, Susana (eds.).Subjetividad y figuras de la memoria. Buenos Aires: Siglo XXI: 17-46;

LONGONI, Ana Traiciones (2007). La figura del traidor en los relatos acerca de los sobrevivientes de la represión. Buenos Aires: Grupo Editorial Norma.

Montero Gómez, Andrés. "Psicopatología del Síndrome de Estocolmo: ensayo de un modelo etiológico". Ciencia policial 51 (1999). ResearchGate. Web. 11 de agosto de 2016.

QuiÑONES URQUiZA, María Laura (2008). “Consideraciones criminológicas sobre el síndrome de Estocolmo” Noticias jurídicas. [Consulta: 26/6/2017].

REATI, Fernando. Insula: revista de letras y ciencias humanas. Vol. 711 (2006): 27-31.

SCHILD, Verónica. "Feminismo y neoliberalismo en América Latina” Nueva Sociedad 265 (2016).

S.A. FILM AFFINITY. Estocolmo.

S.A. BBC Mundo (marzo de 2018). "Captor vs. Cautivo, 40 años del Síndrome de Estocolmo" (23 de agosto 2013). [Consulta: 21 de marzo de 2018].

VV.AA. DSM-IV Manual Diagnóstico y Estadístico de los Trastornos Mentales. 
WORLD Justice PROJECT.

WORNAT, Olga. “Amores clandestinos,” Noticias (14 de marzo del 1998):18-24.

WornAt, Olga y LEWIN, Miriam (2014). Putas y guerrilleras. Buenos Aires: Planeta.

\section{FILMOGRAFÍA}

Estocolmo: Identidad perdida (Netflix/StoryLab y Kapow, 2016). 